\title{
INTRODUÇÃO À LÓGICA MATEMÁTICA COM O JOGO “MEMÓRIA LÓGICA”.
}

Amanda Santos Silva ${ }^{1}$, Antônio Carlos Tamarozzi ${ }^{2}$.

Universidade Federal de Mato Grosso do Sul, Licenciatura em Matemática, Três Lagoas, Mato Grosso do Sul. e-mail: assilva010@gmail.com.

\section{RESUMO}

O raciocínio lógico foi inserido no ensino fundamental e ensino médio com o intuito de despertar o interesse e atenção dos alunos por meio de atividades lúdicas, situações problemas desafiadoras e criativas, que possibilitem a aprendizagem e a compreensão de conceitos matemáticos e sua aplicação em práticas sociais contribuindo para a sua formação como cidadão. $O$ trabalho apresentou uma proposta em forma de jogo como material didático para utilização na disciplina "Raciocínio lógico" nas escolas do estado de Mato Grosso do Sul. Discutimos os detalhes do desenvolvimento do material, sua aplicação em sala, sua utilização como apoio à esta disciplina recém inserida na estrutura curricular dos ensinos fundamental e médio do estado. Apresenta também alguns resultados, obtidos através da aplicação em sala de aula.

Palavras-chave: raciocínio lógico, proposições, jogo, material de apoio, equivalência.

\section{INTRODUCTION TO MATHEMATIC LOGICAL WITH THE GAME “LOGICAL MEMORY”.}

\begin{abstract}
The logical reasoning was included in primary and secondary education with the intention to awake the interest and attention of students through playful activities, challenging and creative situations problems, that enable the learning and comprehension of mathematical concepts and its applications in social practices contributing to the learning as citizen. The current work presents a proposal in form of a game as didactical material to apply in the discipline "logical reasoning" in the schools at Mato Grosso do Sul. We discuss details of the development material, its application in classroom, its application as a support to this newly inserted discipline in the curricular structure of midschool and highschool in this state. It also presents some results obtained through the application in the classroom.
\end{abstract}

Keywords: logical reasoning, propositions, game, didactical material, equivalence. 


\section{INTRODUÇÃO}

Segundo o Referencial curricular de Mato Grosso do Sul, o raciocínio lógico foi inserido no ensino fundamental e médio com o intuito de despertar o interesse e atenção dos alunos por meio de atividades lúdicas, situações problemas desafiadoras e criativas, que possibilitem a aprendizagem e a compreensão de conceitos matemáticos e sua aplicação em práticas sociais contribuindo para a sua formação como cidadão. Com a repentina mudança na grade curricular, notou-se que a maioria dos professores já atuante não teve contato suficiente com o tema em sua formação docente não conseguindo assim elaborar materiais lúdicos que pudessem facilitar a aprendizagem.

Pensando neste quesito, o Programa de Educação Tutorial do curso de Matemática (PET-MAT) da UFMS/CPTL elaborou o jogo "Memória Lógica", onde o objetivo é que o aluno desenvolva a percepção que uma mesma proposição pode ser descrita de formas diferentes, através dos conectivos lógicos, preservando o significado.

\section{METODOLOGIA}

A idéia é que este material poderá ser confeccionado em sala, de forma que professor pode optar por transformar $\mathrm{p}$ e q em proposições literais, isto será adequado, por exemplo, em turmas iniciantes no assunto. Sugerem-se proposições desvinculadas para que o aluno não misture lógica de contexto com lógica dedutiva.

O material é confeccionado em cartolina, e cortado na forma de cartões de $8.6 \mathrm{~cm}$ por $5.4 \mathrm{~cm}$. O jogo é composto por 22 cartas onde 11 são proposições lógicas e as outras 11 são proposições correspondentes equivalentes. Por exemplo, " $p \rightarrow q$ - Se chove então vou ao cinema" faz par com " $q \rightarrow \sim p$ - Se não vou ao cinema então não chove", enquanto que " $\sim(p \vee q)$ - Não é verdade que chove ou vou ao cinema" faz par com " $p \wedge \sim q-$ Não chove e não vou ao cinema" pois denotam equivalências. A sala deve ser dividida em duplas. Será entregue a cada dupla 24 cartas. As cartas deverão ser dispostas em 4 linhas e 6 colunas de forma que os alunos possam ver o que está escrito. Será dado 1 minuto para que os alunos memorizem as posições das cartas correspondentes. Em seguida, deverão virar todas as cartas para baixo e se iniciará o jogo. Cada jogador deverá virar duas cartas; se elas formarem um par, o jogador pontuará e poderá jogar novamente; se elas não formarem um par, o jogador deverá desvirar as cartas e aguardar a sua vez. Segue abaixo na Figura 1 um exemplo de como as cartas podem estar confeccionadas, sendo que o professor é livre a alterar o conteúdo dependendo da necessidade de cada turma.

Para a confecção é necessário apenas uma aula, em torno de 50 minutos, mas para a aplicação é necessário uma revisão prévia, para que os alunos amadureçam o assunto, para que assim seja ministrado o jogo. 


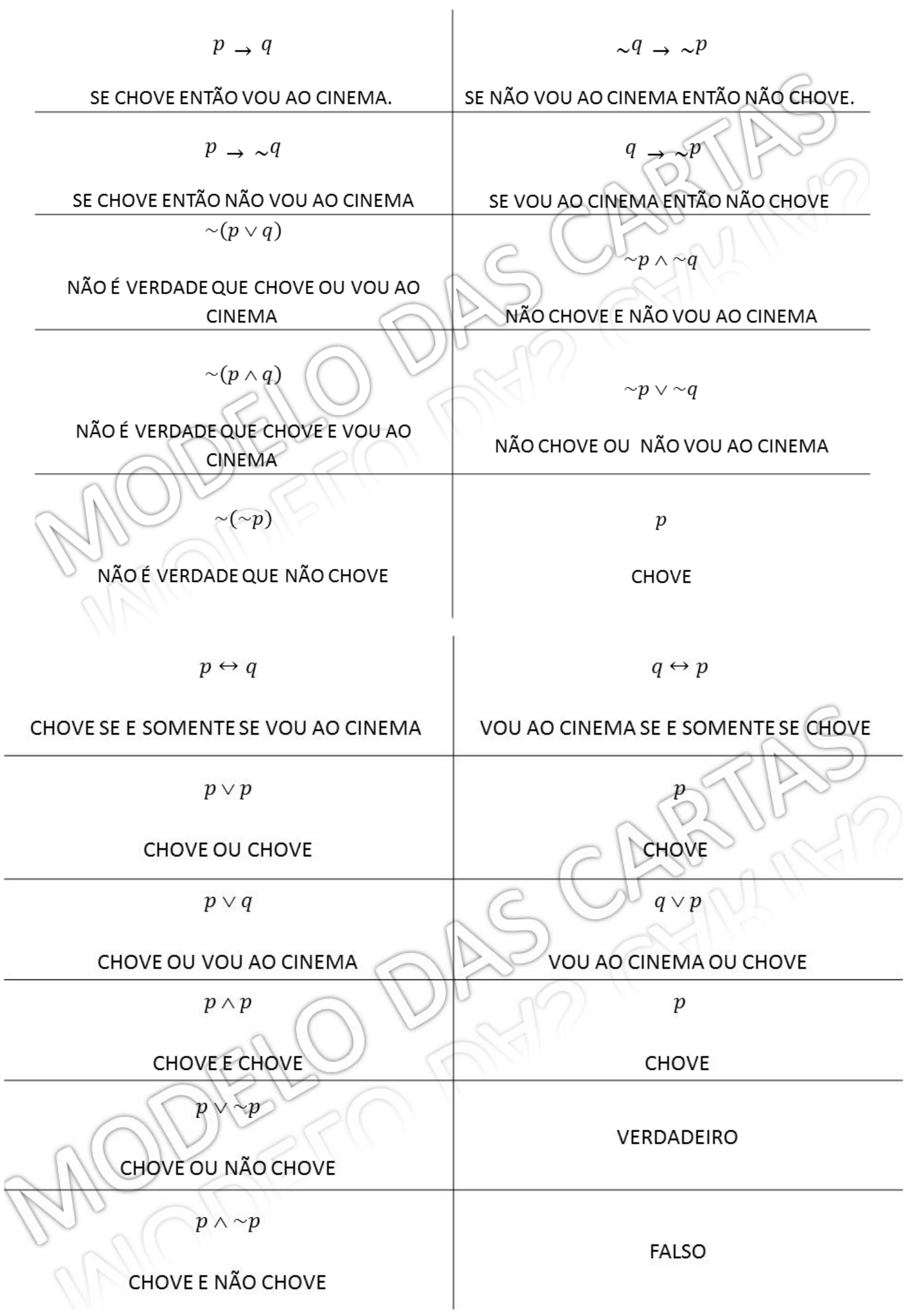

Figura 1. Modelo das Cartas

\section{RESULTADOS}

O material foi aplicado inicialmente junto aos alunos do PET que estão estudando Lógica Proposicional, no primeiro semestre do curso de Licenciatura em Matemática. Foram detectados alguns ajustes necessários e então foi aplicado aos alunos do 30 do Ensino Médio da escola Estadual João Dantas Filgueiras. Com o auxílio do professor, separamos a classe, e explicamos como seria o funcionamento do jogo. Para este público, foi realizado uma revisão de conectivos 
lógicos e a formação de proposições equivalentes. Avaliamos que a receptividade do jogo pelos alunos foi boa. Notadamente ficou claro que a percepção do funcionamento e a aprendizagem dos conteúdos nas partidas subsequentes foi melhorando.

Os bolsistas PET se dividiram pela sala, e ficaram a disposição das duplas para quaisquer dúvidas.

Ao aplicar a atividade em sala, verificamos que os alunos ficaram bem interessados pois ainda não haviam tido contato com jogos com esta temática. Notamos algumas dificuldades quanto as relações que tinham de estabelecer para que se pudesse fazer os pares. No final das partidas foi necessário que se fizesse a conferência dos pares; e lhes perguntamos o porque os pares faziam sentido.

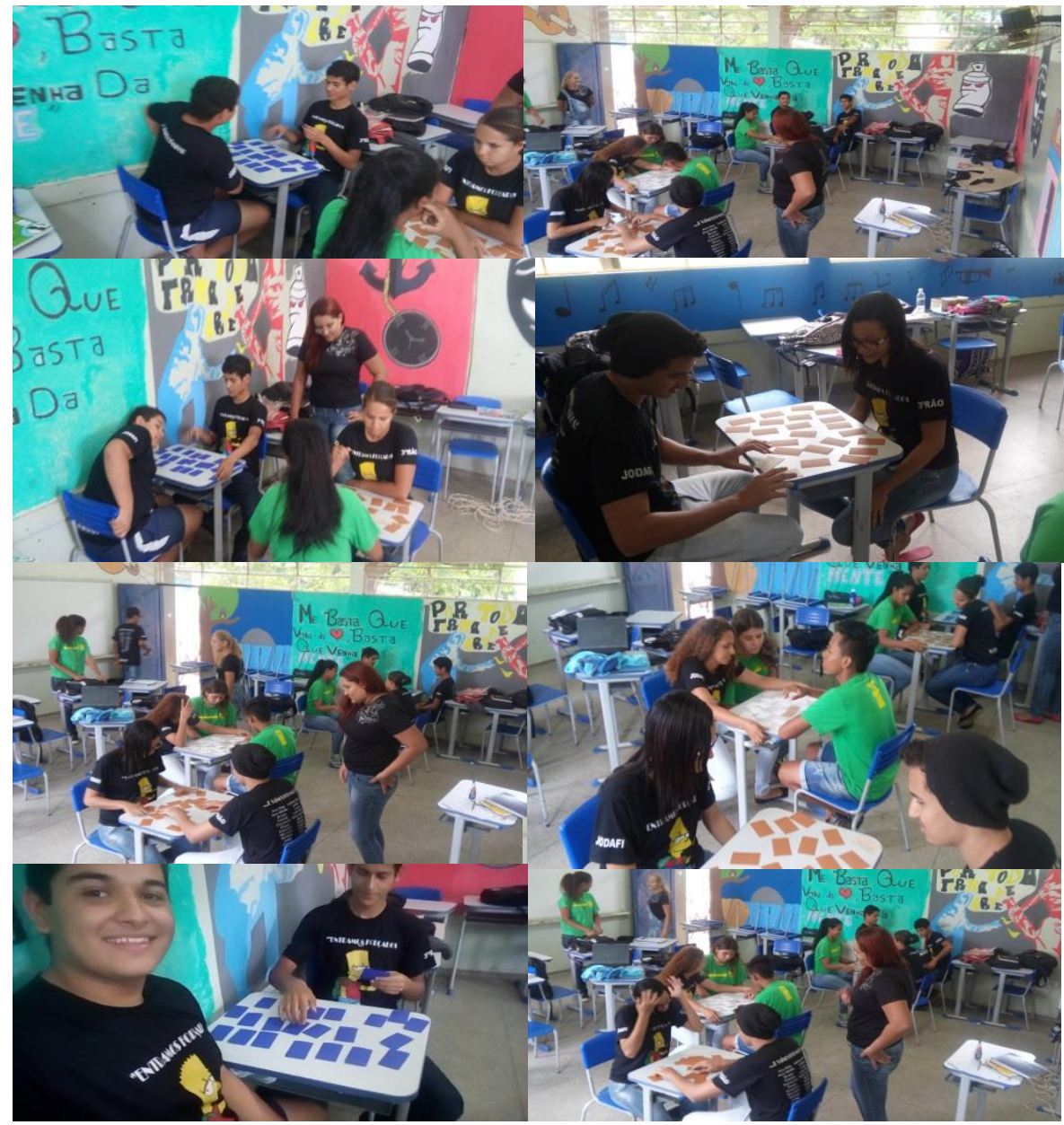

Figura 2. Aplicando o jogo em sala

\section{DISCUSSÃO}

Podem ser explorados os conectivos lógicos (negação), ^ (conjunção), v (disjunção), $\rightarrow$ (condicional) e $\leftrightarrow$ (bicondicional) que são combinados em relações lógicas. Este material deverá ser aplicado pelo professor quando este sentir que os alunos já possuem certa intimidade com o conteúdo de lógica, podendo ser levado do 5으.F ao 3으.M.M.

Há também uma abertura ao professor caso ele queira aprofundar alguns conceitos de lógica permitindo que o aluno faça inferências com os conectivos da lógica proposicional, desde simples leis comutativas da conjunção ou disjunção a contraposições ou leis de De Morgan. Com este material procuramos desenvolver uma atividade lúdica que sirva de apoio para os professores da disciplina de raciocínio lógico de forma simples e intuitiva sem perder todo o rigor e beleza da matemática. 


\section{CONCLUSÃO}

O trabalho veio ao encontro de suprir a necessidade de material lúdico para esta disciplina do ensino básico no estado de Mato Grosso do Sul, desenvolvido pelos bolsistas do grupo PET MAT no intuito de auxiliar o professor na fixação do conteúdo de raciocínio lógico; de forma lúdica, tornando o aprendizado divertido e gratificante. Notou-se tal dificuldade através da deficiência presente nos alunos que ingressaram a Universidade, e a partir disso, foi feito um levantamento com os professores de matemática a dificuldade de transmitir o assunto de forma didática e no trabalho de se encontrar materiais de apoio. O jogo Memória Lógica trabalha com as proposições, conectivos, e a forma literal de tais proposições. O objetivo é que o aluno associe a forma literal à sua proposição, tornando-se íntimo da linguagem matemática. Percebemos que o lúdico se faz necessário, já que material neste conteúdo é escasso. O raciocínio lógico é absolutamente necessário em diversas áreas do cotidiano, tornando-se essencial.

\section{REFERÊNCIAS}

R. M. Vaz, Trabalho de Conclusão de Curso: Formalização do Raciocínio Lógico Baseada na Lógica Matemática, Três Lagoas, 2014.

MATO GROSSO DO SUL. Secretaria de Educação. Referencial Curricular da Rede Estadual de Ensino de Mato Grosso do Sul. Campo Grande: s. n., 2014. p. 10-28.

MORAIS FILHO, Daniel Cordeiro de. Um convite à Matemática. 1. ed. Rio de Janeiro: SBM, 2012. p. 272-287.

ALENCAR FILHO, E. Iniciação à Lógica Matemática. São Paulo: Nobel, 2005.

SOCIEDADE BRASILEIRA DE MATEMÁTICA. Revista do Professor de Matemática. São Paulo: Artigos relacionados ao uso da História da Matemática em sala de aula.

STOCCO SMOLE, katia Cristina. Cadernos do Mathema Ensino Fundamental - Jogos de Matemática de 1ㅇa 5으. Ano. 1 ed. Revinter, 2007. 